pesticidas persistem no solo por muito mais tempo do que o esperado, ou os campos orgânicos foram contaminados por uma via indireta através do ar, água ou partículas do solo provenientes de campos convencionais próximos. Ainda assim, o número de diferentes pesticidas e as suas concentrações diminuíram significativamente quanto maior o tempo em que os campos foram usados para a agricultura biológica. Os investigadores também observaram menor abundância microbiana e diminuição dos níveis de simbiontes benéficos de plantas em campos com níveis mais altos de pesticidas, sugerindo que os resíduos de pesticidas podem diminuir a saúde do solo.
$>$

\section{Ana Paula Esteves}

aesteves@quimica.uminho.pt

\section{Fontes}

How pesticide residues affect organic farms, chemistryviews.org/details/ news/11291728/How_Pesticide_Residues_Affect_Organic_Farms.html (acedido em 16/03/2021).

J. Riedo, F. E. Wettstein, A. Rösch, C. Herzog, S. Banerjee, L. Büchi, R. Charles, D. Wächter, F. M.-Laurent, T. D. Bucheli, F. Walder, M. G. A. van der Heijden, Environ. Sci. Technol. 2021, 55, 2919-2928. DOI: 10.1021/acs.est.0c06405.

\title{
Avelãs - Componentes com Efeitos Benéficos para a Saúde
}

A aveleira (Corylus avellana L.) é uma planta de folha caduca, de porte arbóreo ou arbustivo, nativa do sul da Europa, da Ásia Ocidental e da América do Norte, sendo os seus frutos (avelãs) um alimento comum. As avelãs contêm um alto teor de gorduras, proteínas, fibras e vitaminas, a par com uma grande variedade de metabólitos secundários, que não sendo necessários para o crescimento da planta, podem apresentar diversas atividades biológicas. 0 conhecimento da sua composição química é importante para ajudar a compreender o valor nutricional das avelãs e decidir se alguns dos seus componentes podem ser usados, por exemplo, em alimentos funcionais.

Haji Akber Aisa (Instituto Técnico de Física e Química de Xinjiang e Universidade da Academia Chinesa de Ciências, ambos em Pequim) e seus colegas isolaram, de miolo de avelã, sete glicósidos do ácido indolacético (seis dos quais eram desconhecidos), três alcaloides indole e um neolignano do tipo di-hidrobenzofurano. Os grãos sem casca e moídos foram desengordurados com éter de petróleo e extraídos com metanol. Os investigadores separaram os componentes do extrato metanólico usando técnicas cromatográficas e, após isolamento, as estruturas dos onze compostos referidos acima foram determinadas por espectrometria de massa de ionização por electrospray de alta resolução (HR-ESI-MS), espectroscopia de ressonância magnética nuclear (RMN) e cromatografia gasosa (GC). Os compostos isolados foram testados para atividades anti-inflamatória, antimicrobiana e antioxidante. Cinco dos g'licósidos do ácido indolacético apresentaram atividade anti-inflamatória e três dos compostos isolados mostraram ser ativos contra a levedura Candida albicans. O neolignano do tipo di-hidroben-

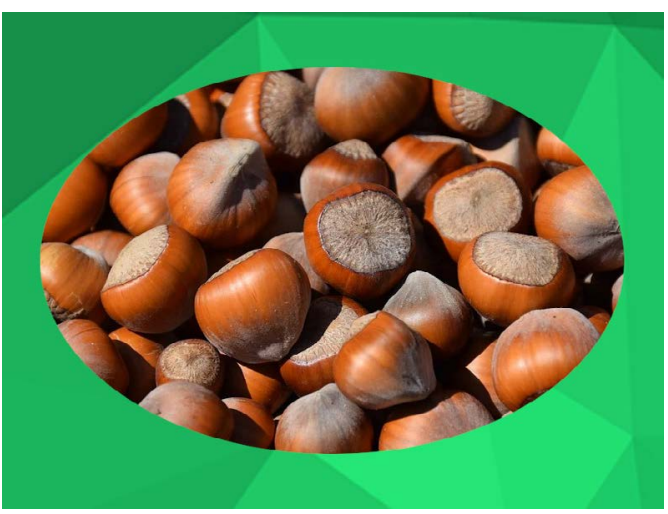

Crédito: ChemistryViews

zofurano apresentou forte atividade antioxidante. Destes resultados é evidente que vários dos novos compostos isolados dos grãos de avelã apresentam atividade biológica promissora. Em combinação com os efeitos benéficos para a saúde descritos anteriormente, estas descobertas podem constituir uma base para estudos adicionais sobre os efeitos na saúde e as potenciais aplicações das avelãs.

$>$

\section{Ana Paula Esteves}

aesteves@quimica.uminho.pt

\section{Fontes}

Hazelnut Components with Beneficial Health Effects, chemistryviews.org/details/ news/11296509/Hazelnut_Components_with_Beneficial_Health_Effects.html (acedido em 31/05/2021).

D. Shataer, J. Li, X.-Mei Duan, L. Liu, X.-Lei Xin, H. A. Aisa, J. Agric. Food Chem. 2021 69, 4111-4119. DOI: 10.1021/acs.jafc.1c00297. 